CARDIOVASCULAR MEDICINE

\title{
Prognostic relations between inflammatory markers and mortality in diabetic patients with non-ST elevation acute coronary syndrome
}

\author{
P L Sanchez, J L Morinigo, P Pabon, F Martin, I Piedra, I F Palacios, C Martin-Luengo
}

Heart 2004;90:264-269. doi: 10.1136/hrt.2002.007443

See end of article for authors' affiliations

Correspondence to: Dr P L Sanchez, Cardiac Unit, University Hospital, Paseo de San Vicente 58 182,37007 , Salamanca, Spain; pedrolsanchez@ hotmail.com

Accepted 16 June 2003

\begin{abstract}
Objective: To determine the differences in the inflammatory status between diabetic and non-diabetic patients and to evaluate the usefulness of $C$ reactive protein, fibrinogen, and leucocyte count as predictors of death in diabetic patients with unstable coronary disease.

Design: Nested case-control comparisons of the inflammatory status between diabetic and non-diabetic patients. Prospective cohort analysis of $\mathrm{C}$ reactive protein concentration, fibrinogen concentration, and leucocyte count as predictors of cardiovascular death in diabetic patients.

Setting: Coronary care unit in Spain.

Participants: 83 diabetic patients with non-ST elevation acute coronary syndrome and 83 sex and aged matched patients selected from 361 non-diabetic patients with non-ST elevation acute coronary syndrome.

Main outcome measures: Plasma concentrations of $C$ reactive protein and fibrinogen, and leucocyte count. Investigators contacted patients to assess clinical events.

Results: Concentrations of $\mathrm{C}$ reactive protein and fibrinogen, and leucocyte count on admission were higher in diabetic than in non-diabetic patients $(7 \mathrm{mg} / \mathrm{l} \vee 5 \mathrm{mg} / \mathrm{l}, \mathrm{p}=0.020 ; 3.34 \mathrm{~g} / \mathrm{l} \vee 2.90 \mathrm{~g} / \mathrm{l}$, $p=0.013$; and $\left.8.8 \times 10^{9} / \mathrm{I} v 7.8 \times 10^{9} / \mathrm{I}, \mathrm{p}=0.040\right)$. Among diabetic patients, these values were also higher in those who died during the 22 month follow up $(13 \mathrm{mg} / \mathrm{l} v 6 \mathrm{mg} / \mathrm{l}, \mathrm{p}=0.001 ; 3.95 \mathrm{~g} / \mathrm{l} v$ $3.05 \mathrm{~g} / \mathrm{l}, \mathrm{p}<0.001$; and $\left.11.4 \times 10^{9} / \mathrm{I} \vee 8.4 \times 10^{9} / \mathrm{l}, \mathrm{p}=0.005\right)$. After adjustment for confounding factors, diabetic patients in the highest tertile of $\mathrm{C}$ reactive protein had a hazard ratio for cardiovascular death of 4.51 (95\% confidence interval (CI) 1.62 to 12.55). Similar hazard ratios were for fibrinogen 3.74 (95\% Cl 1.32 to 10.62 ) and for leucocyte count 3.64 (95\% Cl 1.37 to 9.68$)$.

Conclusions: Inflammation appears more evident in diabetic than in non-diabetic patients with acute coronary syndrome. C reactive protein concentration, fibrinogen concentration, and leucocyte count constitute independent predictors of cardiovascular death in diabetics with unstable coronary disease.
\end{abstract}

Abbreviations: $\mathrm{Cl}$, confidence interval; FRISC, Fragmin during instability in coronary artery disease; NHANES III, national health and nutrition examination survey III 
wave myocardial infarction or Braunwald class IIIB unstable angina from October 1998 to June 2000 were included in the study. Patients with ST elevation at admission (four patients), left bundle branch block (two patients), new Q waves of more than 0.04 seconds in at least two leads (two patients), type 1 diabetes (one patient), malignancy or inflammatory disease (six patients), surgery or major trauma in the previous two months (two patients), valvar heart disease (six patients), patients with previous myocardial infarction and ejection fraction $<40 \%$ (four patients), time from onset of symptoms to admission to the coronary care unit $>12$ hours (five patients), and creatinine $\geqslant 176 \mu \mathrm{mol} / \mathrm{l}$ were excluded from the study (four patients). To compare the differences in the inflammatory status between diabetic and non-diabetic patients, the study group was sex and age matched to 83 of 361 non-diabetic patients admitted to our coronary care unit with the same diagnosis and in the same period of time. All patients were initially treated medically and underwent coronary angiography and revascularisation when refractory or incapacitating angina and signs of severe ischaemia during exercise testing were present. Patients were followed up in a prospective manner. After patients were discharged, investigators contacted patients to assess clinical events. Clinical follow up was available for all patients (100\%). Median follow up of diabetic patients was 22 months.

\section{Laboratory assays and study protocol}

Venous blood samples were obtained from all patients at the time of admission to the coronary care unit. $\mathrm{C}$ reactive protein concentrations were determined by turbidimetry with a commercially available kit (Hitachi model 717, Boehringer Mannheim, Mannheim, Germany). The lower detection limit was $1.3 \mathrm{mg} / \mathrm{l}$. The interassay coefficient of variation was $6 \%$ and the intra-assay coefficient was $1.3 \%$. A comparison of the $\mathrm{C}$ reactive protein determination with a nephelometric method gave a correlation coefficient of 0.991. Plasma concentrations of fibrinogen were measured by use of the Clauss method. Troponin I concentrations were measured by a paramagnetic particle chemiluminescent immunoenzymatic assay. Diabetes mellitus was defined as a fasting serum glucose concentration of $7.0 \mathrm{mmol} / \mathrm{l}(126 \mathrm{mg} / \mathrm{dl})$ or more, a non-fasting glucose concentration of $11.1 \mathrm{mmol} / \mathrm{l}$ $(200 \mathrm{mg} / \mathrm{dl})$ or more, the participant's report of a physician's diagnosis of diabetes, or current use of diabetes medication. ${ }^{30}$

\section{Statistical analysis}

$\mathrm{C}$ reactive protein and fibrinogen concentrations and leucocyte count are presented as median and interquartile range. Non-parametric tests were used to compare $C$ reactive protein and fibrinogen concentrations and leucocyte counts between groups (Mann-Whitney $U$ test) and to determine correlations (Spearman's $\mathrm{p}$ test). Discontinuous variables were tested by a contingency $\chi^{2}$ test. Diabetic patients were divided into tertiles on the basis of their $\mathrm{C}$ reactive protein and fibrinogen concentrations and leucocyte counts at admission. Diabetic patients in the highest tertile were compared with those with concentrations in the two lower tertiles. By forward stepwise logistic regression analysis, we calculated the relative odds ratios and 95\% confidence intervals (CIs) for in-hospital cardiac death. We used Cox regression analyses with forward stepwise selection to calculate the adjusted hazard ratios and 95\% CIs for death from cardiovascular causes for the total follow up period. Logistic and Cox regression analyses considered age $\geqslant 65$ years, sex, body mass index, current smoking, presence or absence of hypertension, previous coronary artery disease, presence or absence of a history of hyperlipidaemia, two or more anginal events in the previous 24 hours, ST segment depression $\geqslant 0.5 \mathrm{~mm}$ at admission, troponin $\mathrm{I}>0.2 \mathrm{ng} / \mathrm{ml}$ on admission, diabetes treatment status, and the presence or absence of prior treatment with aspirin and statins. $C$ reactive protein and fibrinogen concentrations and leucocyte count were thus entered as dichotomised variables, upper tertile versus lower tertile. For comparison with recent studies, ${ }^{31}$ we evaluated the additive effect of $\mathrm{C}$ reactive protein and fibrinogen concentrations and leucocyte count in combination. We categorised diabetic patients on the basis of the number of increased inflammatory markers on admission: none, one, two, or all three. For the present analysis we used a cut off value of $10 \mathrm{mg} / \mathrm{l}$ for $\mathrm{C}$ reactive protein, ${ }^{32} 10000$ cells/ $\mathrm{dl}$ for leucocyte count, ${ }^{28}$ and $>4.00 \mathrm{~g} / \mathrm{l}$ for fibrinogen. ${ }^{29}$

Finally, event-free survival was analysed by the KaplanMeier method and the log rank test was used for to compare curves. A two sided probability value of $\mathrm{p}<0.05$ was considered significant.

\section{RESULTS}

Table 1 shows the baseline clinical characteristics of nondiabetic and diabetic patients. There were no differences in baseline characteristics between groups except for a higher smoking history in non-diabetic patients (43 (51.8\%) $v 27$ $(32.5 \%), p=0.01)$. Almost one third of the patients in both groups had had a previous myocardial infarction, were taking aspirin at admission, and had higher concentrations of troponin I. Approximately $46 \%$ of non-diabetic and 55\% of diabetic patients had ST segment depression $\geqslant 0.5 \mathrm{~mm}$ on admission to the hospital. The mean time from the onset of chest pain to admission in the coronary care unit for diabetic patients was 4.6 (3.3) hours, similar to that for non-diabetic patients. The median $\mathrm{C}$ reactive protein and fibrinogen concentrations and the leucocyte counts were significantly higher at admission in the diabetic than in the non-diabetic patients (table 1).

The median duration of follow up of diabetic patients was 22 months. Nine $(10.8 \%)$ diabetic patients died during hospitalisation and $18(21.7 \%)$ during the entire follow up time (table 2). Compared with those who survived during the follow up, diabetic patients who died were older and a higher percentage were women. A larger percentage also were not taking statins and had ST segment depression at admission (table 3).

The median $\mathrm{C}$ reactive protein and fibrinogen concentrations and the leucocyte count were higher in diabetic patients who died than in those who survived during hospitalisation ( $18 \mathrm{mg} / \mathrm{l} \vee 6 \mathrm{mg} / \mathrm{l}, \mathrm{p}=0.01 ; 3.89 \mathrm{~g} / \mathrm{l} v 3.18 \mathrm{~g} / \mathrm{l}, \mathrm{p}=0.004$; and $\left.11.7 \times 10^{9} / \mathrm{l} v 8.6 \times 10^{9} / \mathrm{l}, \mathrm{p}=0.054\right)$ and during the entire follow up $(13 \mathrm{mg} / \mathrm{l} v 6 \mathrm{mg} / \mathrm{l}, \mathrm{p}=0.001 ; 3.95 \mathrm{~g} / \mathrm{l} v$ $3.05 \mathrm{~g} / \mathrm{l}, \mathrm{p}<0.001$; and $\left.11.4 \times 10^{9} / 1 v 8.4 \times 10^{9} / \mathrm{l}, \mathrm{p}=0.005\right)$.

The correlation coefficient between $\mathrm{C}$ reactive protein concentration and fibrinogen concentration was 0.43 $(\mathrm{p}<0.001)$, between $\mathrm{C}$ reactive protein concentration and leucocyte count was 0.18 ( $\mathrm{p}=0.105)$, and between fibrinogen concentration and leucocyte count was 0.27 $(\mathrm{p}=0.015)$. The coefficient correlations between troponin $\mathrm{I}$ and each of $\mathrm{C}$ reactive protein concentration, fibrinogen concentration, and leucocyte count at admission were weak and not significant $(0.11,-0.01$, and 0.07 , respectively).

Coronary angiography was performed in 34 diabetic patients (41\%); 13 (15.7\%) before discharge and 21 (25.3\%) during the follow up. No patients had normal coronary arteries (coronary stenosis $<50 \%$ ). Eight, eight, and 18 patients had one, two, or three vessel coronary disease, respectively. Two $(5.9 \%)$ of the 34 diabetic patients had significant left main artery disease. The Kruskal-Wallis one way analysis of variance indicated that there was no relation between the number of diseased coronary arteries and either 


\begin{tabular}{|c|c|c|c|}
\hline & $\begin{array}{l}\text { Non-diabetic } \\
(n=83)\end{array}$ & Diabetic $(n=83)$ & $p$ Value \\
\hline Median age (years) & 71 & 71 & 1.000 \\
\hline Female sex & $26(31.3 \%)$ & $26(31.3 \%)$ & 1.000 \\
\hline Hypertension & $36(43.4 \%)$ & $39(47.0 \%)$ & 0.640 \\
\hline Smoking history & $43(51.8 \%)$ & $27(32.5 \%)$ & 0.012 \\
\hline Hypercholesterolaemia & $46(55.4 \%)$ & $47(56.6 \%)$ & 0.876 \\
\hline Body mass index $\geqslant 25 \mathrm{~kg} / \mathrm{m}^{2}$ & $49(59.0 \%)$ & $52(62.7 \%)$ & 0.633 \\
\hline Stable angina $>3$ months before admission & $22(26.5 \%)$ & $31(37.3 \%)$ & 0.134 \\
\hline Previous myocardial infarction & $22(26.5 \%)$ & $24(28.9 \%)$ & 0.729 \\
\hline Aspirin at admission & $31(37.3 \%)$ & $26(31.3 \%)$ & 0.414 \\
\hline Statins at admission & $13(15.7 \%)$ & $10(12.0 \%)$ & 0.500 \\
\hline$\geqslant 2$ anginal episodes in previous 24 hours & $37(44.6 \%)$ & $28(33.7 \%)$ & 0.152 \\
\hline$\geqslant S T$ segment depression $\geqslant 0.5 \mathrm{~mm}$ at admission & $38(45.8 \%)$ & $46(55.4 \%)$ & 0.214 \\
\hline Coronary angiography during the study & $39(47.0 \%)$ & $34(41.0 \%)$ & 0.434 \\
\hline One vessel disease & $13(66.7 \%)$ & $8(23.5 \%)$ & 0.356 \\
\hline Multivessel disease & $26(33.3 \%)$ & $26(76.5 \%)$ & 0.356 \\
\hline Troponin I $\geqslant 0.2 \mathrm{ng} / \mathrm{ml}$ at admission* & $32(38.6 \%)$ & $29(34.9 \%)$ & 0.629 \\
\hline $\begin{array}{l}\text { Mean (SD) time from onset of chest pain to } \\
\text { admission (hours) }\end{array}$ & $4.7(3.0)$ & $4.6(3.3)$ & 0.785 \\
\hline Median $\mathrm{C}$ reactive protein $(\mathrm{mg} / \mathrm{l})$ & $5(2,8)$ & $7(3,11)$ & 0.020 \\
\hline Median fibrinogen (g/l) & $2.90(2.44,3.33)$ & $3.34(2.62,3.92)$ & 0.013 \\
\hline Median leucocyłe $\left(\times 10^{9} / \mathrm{l}\right)$ & $7.8(6.5,10.1)$ & $8.8(6.9,11.3)$ & 0.040 \\
\hline
\end{tabular}

\section{Table 2 Cause of death}

\begin{tabular}{ll}
\hline Cause of death & Number \\
\hline Total cardiovascular mortality & $18(21.7 \%)$ \\
In-hospital mortality & $9(10.8 \%)$ \\
Congestive heart failure & 7 \\
Acute, fulminating pulmonary oedema within 24 hours of admission (severe MR) & 2 \\
Acute, fulminating pulmonary oedema $>24$ hours after admission (severe MR) & 1 \\
Hypotension and cardiogenic shock & 2 \\
Cardiorrhexis & 2 \\
Arrhythmias & 1 \\
Reinfarction & 1 \\
Mortality after discharge & $9(10.8 \%)$ \\
Congestive heart failure & 4 \\
Reinfarction & 2 \\
Sudden death & 2 \\
Aortic aneurysm rupture & 1 \\
\hline MR, mitral regurgitation. & \\
Cardiorrhexis was defined as sudden death with electromechanical dissociation. &
\end{tabular}

Table 3 Clinical data of surviving and non-surviving diabetic patients

\begin{tabular}{llll}
\hline & Surviving $(\mathbf{n = 6 5 )}$ & $\begin{array}{l}\text { Non-surviving } \\
\text { (n= 18) }\end{array}$ & p Value \\
\hline Median age (years) & 69 & 76 & 0.001 \\
Female sex & $16(24.6 \%)$ & $10(55.6 \%)$ & 0.012 \\
Hypertension & $31(47.7 \%)$ & $8(44.4 \%)$ & 0.807 \\
Smoking history & $24(36.9 \%)$ & $3(16.7 \%)$ & 0.105 \\
Hypercholesterolaemia & $32(49.2 \%)$ & $11(61.1 \%)$ & 0.372 \\
Body mass index $\geqslant 25 \mathrm{~kg} / \mathrm{m}^{2}$ & $43(66.2 \%)$ & $9(50.0 \%)$ & 0.210 \\
Stable angina $>3$ months before admission & $22(33.8 \%)$ & $9(50.0 \%)$ & 0.210 \\
Previous myocardial infarction & $18(27.7 \%)$ & $6(33.3 \%)$ & 0.640 \\
Aspirin at admission & $20(30.8 \%)$ & $6(33.3 \%)$ & 0.640 \\
Statins at admission & $13(20.0 \%)$ & 0 & 0.039 \\
$\geqslant 2$ anginal episodes in previous 24 hours & $22(33.8 \%)$ & $6(33.3 \%)$ & 0.968 \\
ST segment depression $\geqslant 0.5 \mathrm{~mm}$ at admission & $32(49.2 \%)$ & $14(77.8 \%)$ & 0.031 \\
Troponin I $\geqslant 0.2 \mathrm{ng} / \mathrm{ml}$ at admission* & $20(30.8 \%)$ & $9(50.0 \%)$ & 0.130 \\
Median C reactive protein (mg/l) & $6(3,9)$ & $13(7,39)$ & 0.001 \\
Median fibrinogen (g/l) & $3.05(2.51,3.80)$ & $3.95(3.55,4.65)$ & $<0.001$ \\
Median leucocyte count (10 $/$ /) & $8.4(6.7,10.3)$ & $11.4(8.7,12.9)$ & 0.005 \\
\hline *Twice the upper limit of the authors' laboratory. & & & \\
\hline
\end{tabular}

C reactive protein concentration $(p=0.453)$, fibrinogen concentration $(p=0.126)$, or leucocyte count $(p=0.548)$. No association was found between concentrations of the three inflammatory markers or with lesion morphology.
Table 4 shows the incidence of clinical events according to tertiles in which diabetic patients were divided on the basis of their $\mathrm{C}$ reactive protein and fibrinogen concentration and their leucocyte counts at admission. The Kaplan-Meier analysis 
Table 4 Incidence of cardiovascular death and events during hospitalisation and follow up

\begin{tabular}{|c|c|c|c|c|c|}
\hline & & Tertile 1 & Tertile 2 & Tertile 3 & p Value \\
\hline \multirow[t]{7}{*}{$C$ reactive protein } & Range (mg/l) & $<5$ & $5-8$ & $>8$ & \\
\hline & Number & 28 & 26 & 29 & \\
\hline & Follow up mortality & $1(3.6 \%)$ & $5(19.2 \%)$ & $12(41.4 \%)$ & 0.002 \\
\hline & In-hospital mortality & $1(3.6 \%)$ & $1(3.8 \%)$ & $7(24.1 \%)$ & 0.017 \\
\hline & Follow up revascularisation & $5(17.4 \%)$ & $10(38.5 \%)$ & $6(20.7 \%)$ & 0.171 \\
\hline & In-hospital revascularisation & $3(10.7 \%)$ & $2(7.7 \%)$ & $2(6.9 \%)$ & 0.863 \\
\hline & Follow up reinfarction & $3(10 . \% 7)$ & $3(11.5 \%)$ & $5(17.2 \%)$ & 0.733 \\
\hline \multirow[t]{7}{*}{ Fibrinogen } & Range (g/l) & $<2.81$ & $2.81-2.78$ & $>2.78$ & \\
\hline & Number & 28 & 27 & 28 & \\
\hline & Follow up mortality & $1(3.6 \%)$ & $6(22.2 \%)$ & $11(39.3 \%)$ & 0.005 \\
\hline & In-hospital mortality & 0 & $3(11.1 \%)$ & $6(21.4 \%)$ & 0.036 \\
\hline & Follow up revascularisation & $8(28.6 \%)$ & $9(33.3 \%)$ & $4(14.3 \%)$ & 0.096 \\
\hline & In-hospital revascularisation & $5(17.9 \%)$ & $1(3.7 \%)$ & $1(3.6 \%)$ & 0.088 \\
\hline & Follow up reinfarction & $5(17.9 \%)$ & $1(3.7 \%)$ & $5(17.9 \%)$ & 0.205 \\
\hline \multirow{7}{*}{ Leucocyte count } & Range $\left(\times 10^{9} / \mathrm{I}\right)$ & $<7.5$ & $7.6-10.2$ & $>10.3$ & \\
\hline & Number & 29 & 26 & 28 & \\
\hline & Follow up mortality & $4(13.8 \%)$ & $3(11.5 \%)$ & $11(39.3 \%)$ & 0.0214 \\
\hline & In-hospital mortality & $2(6.9 \%)$ & 0 & $7(25.0 \%)$ & 0.009 \\
\hline & Follow up revascularisation & $10(34.5 \%)$ & $7(26.9 \%)$ & $4(14.3 \%)$ & 0.807 \\
\hline & In-hospital revascularisation & $5(17.2 \%)$ & $2(7.7 \%)$ & 0 & 0.064 \\
\hline & Follow up reinfarction & $4(13.8 \%)$ & $2(7.7 \%)$ & $5(17.9 \%)$ & 0.543 \\
\hline
\end{tabular}

showed that patients with the highest $\mathrm{C}$ reactive protein and fibrinogen concentrations and leucocyte count had a significantly higher probability of death from cardiac causes during the entire follow up period than patients with lower values (fig 1).

Multivariable analysis of the relations between clinical data, myocardial damage markers, findings on the ECG, serum inflammatory markers determined, and the risk of cardiovascular death showed that two variables were significant for in-hospital mortality (C reactive protein concentrations and leucocyte count at admission) and four variables for the entire follow up period ( $\mathrm{C}$ reactive protein, fibrinogen, leucocyte count, and female sex). The adjusted odds ratios for in-hospital mortality were 9.19 (95\% CI 1.60 to 52.74; $p=0.013$ ) for diabetic patients with $\mathrm{C}$ reactive protein in the top third of measurements and for leucocyte count 9.79 (95\% CI 1.71 to 56.04; $p=0.010)$. The hazard ratios for death during the entire follow up were 4.51 (95\% CI 1.62 to 12.55; $\mathrm{p}=0.004$ ) for diabetic patients in the highest tertile of C reactive protein, 3.74 (95\% CI 1.32 to 10.62 ; $\mathrm{p}=0.013$ ) for patients in the highest tertile of fibrinogen, and 3.64 (95\% CI 1.37 to 9.68; p $=0.01$ ) for leucocyte count. Finally, the hazard ratio for female sex diabetic patients was 3.45 (95\% CI 1.30 to $9.09 ; \mathrm{p}=0.013$ ).

Categorising patients on the basis of the number of increased inflammatory markers on admission, $43.5 \%$ had no increased markers, $37.3 \%$ had one, $12 \%$ had two, and $7.2 \%$ had increases in all three. Fig 2 shows adjusted hazard ratios for cardiovascular death in diabetic patients stratified by the number of increased inflammatory markers.

\section{DISCUSSION}

Coronary tissue from diabetic patients with acute coronary syndrome has more lipid rich atheroma, thrombosis, and macrophage cell infiltration than tissue from patients without diabetes. This higher incidence of inflammatory cell infiltration in coronary tissue from diabetic patients suggests not only that inflammation may play an important part in the pathophysiology of acute coronary syndrome but also that a more proinflammatory state is present in diabetic than in non-diabetic patients. The observation of increased concentrations of $\mathrm{C}$ reactive protein and other acute phase reactants in diabetes is not new; reports date back to the 1980s. Among $>16000$ patients in the NHANES III (national health and nutrition examination survey $\mathrm{III}$ ), $\mathrm{C}$ reactive protein was shown to be higher in patients with diabetes or glucose intolerance than in control participants. ${ }^{33}{ }^{34}$ In consideration of the overlap between inflammatory status and diabetes, some authors have also looked at the association between these two conditions among patients with acute coronary syndrome. In the FRISC (Fragmin during instability in coronary artery disease) study diabetes and $\mathrm{C}$ reactive protein concentrations on admission were shown to be independent predictors of long term outcome. ${ }^{23}$ Interestingly, in some series the presence of diabetes has been associated, independent of the prognosis, with increased $C$ reactive protein concentrations, ${ }^{24}{ }^{25}$ whereas in other studies the two parameters appeared to be independent. ${ }^{26}$ In our study diabetic patients with acute coronary disease had an enhanced underlying inflammatory reaction, as their $\mathrm{C}$ reactive protein concentrations, fibrinogen concentrations, and leucocyte counts at admission were higher than in non-diabetics. Myocardial necrosis may account for some of the increase found in $\mathrm{C}$ reactive protein, fibrinogen, and leucocytes. However, troponin I concentrations were similar at admission in both groups and the correlations between troponin I and C reactive protein, fibrinogen, or leucocytes in diabetic patients were also weak, as previous studies of nondiabetic patients have shown..$^{23} 27$

Diabetic patients who suffer a myocardial infarction have a high mortality both acutely and on long term follow up. This increased in-hospital mortality among diabetic patients with acute coronary syndromes is attributable predominantly to a higher increased incidence of reinfarction and recurrent ischaemia, and mainly to congestive heart failure. ${ }^{35-37}$ Furthermore, cardiogenic shock is more common and more severe in diabetic patients than would be expected from the size of the index infarction. ${ }^{38}$ Despite the size of the infarction, pre-existing diastolic dysfunction and reduced global and regional left ventricular ejection fraction of the non-infarcted myocardium ${ }^{39}$ are major culprits of the congestive symptoms. Late mortality is principally related to recurrent myocardial infarction and the development of new congestive heart failure. ${ }^{36}{ }^{38}$ We also found that congestive heart failure was the main contributing factor not only of inhospital mortality (78\%) but also of late mortality (44\%). Our finding of enhanced inflammatory response may explain the higher mortality found in diabetic patients after unstable coronary disease and may help future treatments-glycoprotein IIb/IIIa inhibitor, aspirin, and some cholesterol lowering drugs exert a beneficial influence on inflammation markers and clinical outcomes. ${ }^{41}$ 

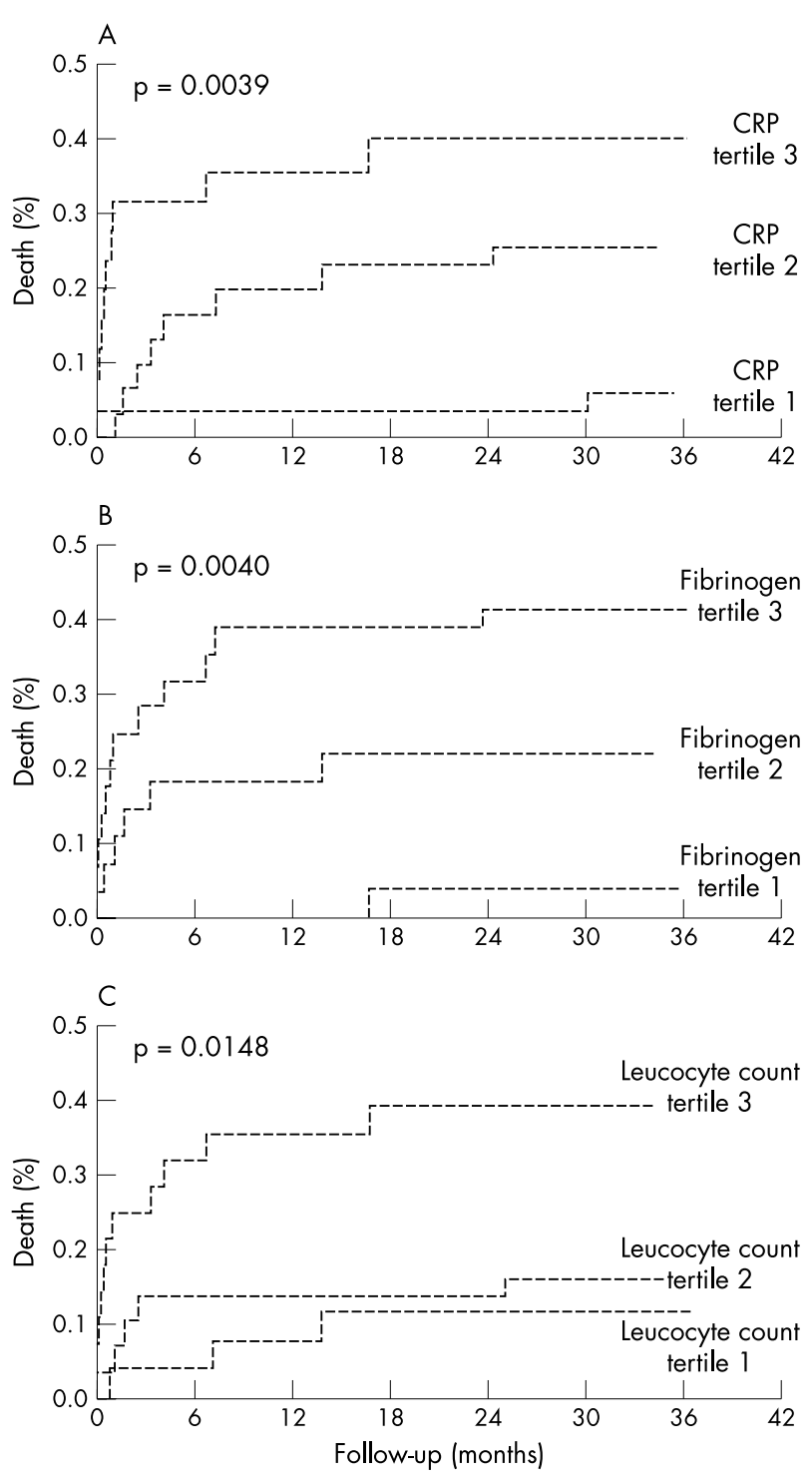

Figure 1 Kaplan-Meier survival estimates for diabetic patients divided into tertiles according to (A) C reactive protein concentrations, (B) fibrinogen concentrations, and (C) leucocyte count on admission.

A variety of clinical studies have been carried out to investigate different markers of inflammation as predictors of coronary events in patients with unstable angina and after myocardial infarction. Although several of them have been shown to predict risk independently of conventional risk factors, the question remains which marker should be preferred in the routine clinical setting. To our knowledge very limited information is available concerning diabetic patients, although one of the goals of this study was to evaluate and compare the usefulness of $\mathrm{C}$ reactive protein concentration, fibrinogen concentration, and leucocyte count as predictors of death in diabetic patients. The association between these serum inflammatory markers in diabetic patients and the risk of death was independent of the presence or absence of other classical risk factors: troponin I concentration, electrocardiographic changes, prior treatment with aspirin or statins, and other known predictors of the risk of death. Leucocyte count and C reactive protein concentration were strong and similar predictors of in-hospital mortality in our study, and both were superior to fibrinogen concentration. C reactive protein developed as the most significant predicting factor of cardiovascular death in the

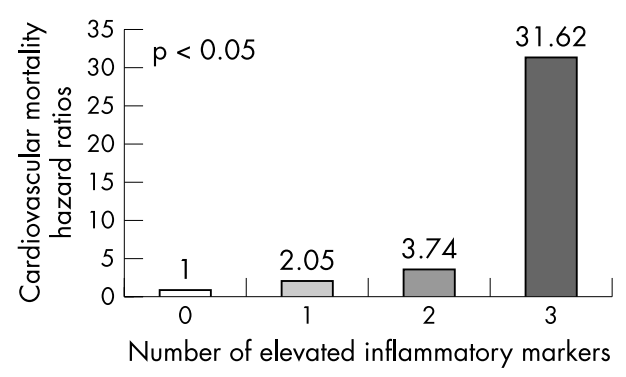

Figure 2 Cardiovascular death hazard ratios in diabetic patients based on the number of increased inflammatory markers.

entire follow up. As leucocyte count is widely assessed in patients admitted with acute coronary syndrome we must not forget that it may provide clinicians with a simple tool for risk stratification. In our opinion, our data suggest that at admission $C$ reactive protein concentration should be routinely determined in the initial evaluation of diabetic patients admitted with acute coronary syndrome. Simultaneous assessment of $\mathrm{C}$ reactive protein concentration, fibrinogen concentration, and leucocyte count also provides prognostic information and may have practical clinical applications in risk stratification and targeting of treatment of diabetic patients with unstable coronary disease. Moreover, categorising diabetic patients based on the number of increased inflammatory markers may counteract the intraindividual variability in the estimation of these inflammatory markers. ${ }^{42}$

\section{Conclusions}

Our study showed enhanced underlying inflammatory reaction in diabetic patients with acute coronary disease as shown by $\mathrm{C}$ reactive protein concentration, fibrinogen concentration, and leucocyte count on admission that were higher than those of non-diabetic patients. More interestingly, these markers of inflammation are independent predictors of cardiovascular death in diabetics with unstable non-ST elevation acute coronary syndrome.

\section{ACKNOWLEDGEMENTS}

Thanks to Dr Carla Criado, Dr Jesus Herrero, and Dr Pablo Prieto for their participation in the collection of data.

\section{Authors' affiliations}

P L Sanchez, J L Morinigo, P Pabon, F Martin, I Piedra, I F Palacios,

C Martin-Luengo, Cardiac Unit, University Hospital, Salamanca, Spain

\section{REFERENCES}

1 Stamler J, Vaccaro O, Neaton JD, et al. Diabetes, other risk factors, and 12-yr cardiovascular mortality for men screened in the multiple risk factor intervention trial. Diabetes Care 1993;16:434-44.

2 Schwartz CJ, Valente AJ, Sprague EA, et al. Pathogenesis of the atherosclerotic lesion. Implication for diabetes mellitus. Diabetes Care 1992; 15:1156-67.

3 Haffner SM, Lehto S, Ronnemaa T, et al. Mortality from coronary heart disease in subjects with type 2 diabetes and in nondiabetic subjects with and without prior myocardial infarction. N Engl J Med 1998;339:229-34.

4 Siegel RD, Cupples A, Schaefer EJ, et al. Lipoproteins, apolipoproteins, and low-density lipoprotein size among diabetics in the Framingham offspring study. Metabolism 1996:45:1267-72.

5 Stamler J, Vaccaro O, Neaton JD, et al. The multiple risk factor intervention trial group: diabetes, other risk factors and 12-year cardiovascular mortality for men screened in the multiple risk factor intervention trial. Diabetes Care 1993; 16:434-44.

6 Sowers JR. Obesity and cardiovascular disease. Clin Chem 1998:44:1821-5.

7 Tschoepe D, Roesen P, Schwippert B, et al. Platelets in diabetes: the role in the hemostatic regulation in atherosclerosis. Semin Thromb Hemost 1993;19:122-8.

8 Kannel WB, D'Agostino RB, Wilson PW, et al. Diabetes, fibrinogen, and the risk of cardiovascular disease: the Framingham experience. Am Heart $J$ 1990; 120:672-6. 
9 Schneider DJ, Nordt TK, Sobel BE. Attenuated fibrinolysis and accelerated atherogenesis in type II diabetes patients. Diabetes 1993;42:1-7.

10 Nordt TK, Schneider DJ, Sobel BE. Augmentation of the synthesis of plasminogen activator inhibitor type-1 by precursor of insulin. A potential risk factor for vascular disease. Circulation 1994:89:321-30.

11 Ferranini E, Haffner SM, Mitchell BM, et al. Hyperinslulinaemia: the key feature of a cardiovascular and metabolic syndrome. Diabetologia $1991 ; 34: 416-22$

12 Baynes JW, Thorpe SR. Role of oxidative stress in diabetic complications: a new perspective on and old paradigm. Diabetes 1999;48:1-9.

13 Reaven GM, Lithell H, Landsberg L. Hypertension and associated metabolic abnormalities- the role of insulin resistance and the sympathoadrenal system. N Engl J Med 1996;334:374-82

14 Bucala R, Makita Z, Koschinsky T, et al. Lipid advanced glycosylation: pathway for lipid oxidation in vivo. Proc Natl Acad Sci USA 1993;90:6434-8

15 Pradhan AD, Ridker PM. Do atherosclerosis and type 2 diabetes share a common inflammatory basis? Eur Heart J 2002;23:831-4.

16 Biondi-Zoccai GGL, Abbate A, Liuzzo G, et al. Atherothrombosis, inflammation, and diabetes. J Am Coll Cardiol 2003;41:1071-7.

17 Moreno PR, Murcia AM, Palacios IF, et al. Coronary composition and macrophage infiltration in atherectomy specimens from patients with diabetes mellitus. Circulation 2000;102:2180-4.

18 Freeman DJ, Norrie J, Caslake MJ, et al. C-reactive protein is an independent predictor of risk for the development of diabetes in the west of Scotland coronary prevention study. Diabetes 2002;51:1596-600.

19 Ford ES. Leukocyte count, erythrocyte sedimentation rate, and diabetes incidence in a national sample of U.S. adults. Am J Epidemiol 2002; 155:57-64.

20 Freeman DJ, Norrie J, Sattar N, et al. Pravastatin and the development of diabetes mellitus: evidence for a protective treatment effect in the west of Scotland coronary prevention study. Circulation 2001;103:357-62.

21 Buchanan TA, Xiang AH, Peters RK, et al. Preservation of pancreatic beta-cell function and prevention of type 2 diabetes by pharmacological treatment of insulin resistance in high-risk Hispanic women. Diabetes 2002;51:2796-803.

22 Anon. Effects of an angiotensin-converting-enzyme inhibitor, ramipril, on cardiovascular events in high-risk patients. The Heart Outcome Prevention Evaluation Study Investigators. N Engl J Med 2000;342: 145-53

23 Lindahl B, Toss H, Siegbahn A, for the FRISC Study Group, et al. Markers of myocardial damage and inflammation in relation to long-term mortality in unstable coronary artery disease. FRISC study group. Fragmin during instability in coronary artery disease. N Engl J Med 2000;343:1139-47.

24 Ferreiros ER, Boissonnet CP, Pizarro R, et al. Independent prognostic value of elevated $C$-reactive protein in unstable angina. Circulation 1999; 100:1958-63.

25 Morrow DA, Rifai N, Antman EM et al. C-reactive protein is a potent predictor of mortality independently of and in combination with troponin $T$ in acute coronary syndromes: A TIMI 11A substudy. J Am Coll Cardiol 1998;31:1460-5

26 Heeschen C, Hamm CW, Bruemmer J, et al. Predictive value of C-reactive protein and troponin $\mathrm{T}$ in patients with unstable angina: a comparative analysis. CAPTURE Investigators. Chimeric c7E3 antiplatelet therapy in unstable angina refractory to standard treatment trial. J Am Coll Cardiol 2000;35:1535-42.

27 Toss H, Lindahl B, Siegbahn A, et al. Prognostic influence of increased fibrinogen and $\mathrm{C}$-reactive protein levels in unstable coronary artery disease. Circulation 1997;96:4204-10

28 Biasucci LM, Liuzzo G, Grillo RL, et al. Elevated levels of C-reactive protein at discharge in patients with unstable angina predict recurrent instability. Circulation 1999:99:855-60.

29 Cannon CP, McCabe CH, Wilcox RG, et al. Association of white blood cell count with increased mortality in acute myocardial infarction and unstable angina pectoris. Am J Cardiol 2001;87:636-9.

$30 \mathrm{Kahn} \mathrm{R}$, for the American Diabetes Association. Report of the expert committee on the diagnosis and classification of diabetes mellitus. Diabetes Care 1997:20:1183-96.

31 Sabatine MS, Morrow DA, de Lemos JA, et al. Multimarker approach to risk stratification in non-ST elevation acute coronary syndromes. Simultaneous assessment of troponin I, C-Reactive protein, and B-Type natriuretic peptide. Circulation 2002;105:1760-3.

32 Pearson TA, Mensah GA, Alexander RW, et al. Markers of inflammation and cardiovascular disease: application to clinical and public health practice: a statement for healthcare professionals from the Centers for Disease Control and Prevention and the American Heart Association. Circulation 2003; 107:499-511.

33 McMillan DE. Increased levels of acute phase serum proteins in diabetes. Metabolism 1989;38:1042-6.

34 Ford ES. Body mass index, diabetes, and C-reactive protein among US adults. Diabetes Care 199, 22:1971-7.

35 Malmberg K, Ryden L. Myocardial infarction in patients with diabetes mellitus. Eur Heart J 1988;9:259-64.

36 Stone PH, Muller JE, Hartwell T, et al. The effect of diabetes mellitus on prognosis and serial left ventricular function after acute myocardial infarction: contribution of both coronary disease and diastolic left ventricular dysfunction to the adverse prognosis. The MILIS Study Group. J Am Coll Cardiol 1989;14:49-57.

37 Ulvenstam G, Aberg A, Bergstrand R, et al. Long-term prognosis after myocardial infarction in men with diabetes. Diabetes 1985;34:787-92.

38 Jaffe AS, Spadaro JJ, Schechtman K, et al. Increased congestive hear failure after myocardial infarction of modest extent in patients with diabetes mellitus. Am Heart J 1988; 108:31-7.

39 Iwasaka T, Takahashi N, Nakamura S, et al. Residual left ventricular pump function after acute myocardial infarction in NIDDM patients. Diabetes Care 1992; 15:1522-6.

40 Takahashi N, Iwasaka T, Sugiura T, et al. Left ventricular regional function after acute anterior myocardial infarction in diabetic patients. Diabetes Care $1989 ; 12: 630-5$

41 Albert MA, Danielson E, Rifai N, et al. Effect of statin therapy on C-reactive protein levels: the pravastatin inflammation/CRP evaluation (PRINCE): a randomised trial and cohort study. JAMA 2001;286:64-70.

42 Clark GH Fraser CG. Biological variation of acute phase proteins. Ann Clin Biochem 1993;30:373-6.

\section{FROM BMJ JOURNALS}

\section{Nurse initiated thrombolysis in the accident and emergency department: safe, accurate, and faster than fast track}

\section{S M Heath, R J I Bain, A Andrews, S Chida, S I Kitchen, M I Walters}

Please visit the Heart website [www.heartinl. com] for a link to the full text of this article.
Objective: To reduce the time between arrival at hospital of a patient with acute myocardial infarction and administration of thrombolytic therapy (door to needle time) by the introduction of nurse initiated thrombolysis in the accident and emergency department. Methods: Two acute chest pain nurse specialists (ACPNS) based in A\&E for 62.5 hours of the week were responsible for initiating thrombolysis in the A\&E department. The service reverts to a "fast track" system outside of these hours, with the on call medical team prescribing thrombolysis on the coronary care unit. Prospectively gathered data were analysed for a nine month period and a head to head comparison made between the mean and median door to needle times for both systems of thrombolysis delivery.

Results: Data from 91 patients were analysed; 43 (47\%) were thrombolysed in A\&E by the ACPNS and $48(53 \%)$ were thrombolysed in the coronary care unit by the on call medical team. The ACPNS achieved a median door to needle time of 23 minutes ( $\mathrm{IQR}=17$ to 32 ) compared with 56 minutes (IQR $=34$ to 79.5 ) for the fast track. The proportion of patients thrombolysed in 30 minutes by the ACPNS and fast track system was $72 \%$ ( 31 of 43 ) and $21 \%(10$ of 48$)$ respectively (difference $=51 \%$, 95\% confidence intervals $34 \%$ to $69 \%$, $\mathrm{p}<0.05)$.

Conclusion: Diagnosis of acute myocardial infarction and administration of thrombolysis by experienced cardiology nurses in A\&E is a safe and effective strategy for reducing door to needle times, even when compared with a conventional fast track system.

A Emergency Medicine Journal 2003;20:418-420. 